\title{
Influence of the Madden-Julian Oscillation on East African rainfall: II. March-May season extremes and interannual variability
}

\author{
By BENJAMIN POHL* and PIERRE CAMBERLIN \\ Centre de Recherches de Climatologie, CNRS/Université de Bourgogne, Dijon, France
}

(Received 14 November 2005; revised 18 May 2006)

\section{SUMMARY}

The Madden-Julian Oscillation (MJO) was shown in Part I to have a significant impact on both East African rainy seasons at pentad time-scale. The case of the 'long rains' (March-May) is further examined by considering both shorter (daily) and longer (interannual) time-scales. Based on composite analyses, extreme daily rainfall events in the Highland (west) and in the coastal (east) regions of Equatorial East Africa (Kenya and Tanzania) are extracted. Low-level westerly wind anomalies are seen to accompany wet events in the west and easterly ones in the east. These opposite circulation anomalies preferentially occur at distinct phases of the MJO, which indicates that the latter has a major influence on rainfall at the daily time-scale.

However, this influence undergoes significant year-to-year variations. It is found that the common variance between smoothed rainfall time series (5-day low-pass filter) and MJO indices varies from 5\% to 53\% in the Highland region. Significantly lower air temperatures in the upper troposphere are recorded during the MJO cycles that present the highest common variance with East African rainfall. Such a cooling is seen to be related to the Kelvin wave propagation in the upper layers which favours upward atmospheric motion over the region.

At the interannual time-scale, fluctuations in MJO amplitude contribute to the March-May rainfall variability, and 44\% of the March-May seasonal rainfall variance in the 1979-95 period in East Africa is explained by this parameter. Years of high MJO amplitude are characterized by earlier onset of the rains, and higher seasonal amounts.

KEYWORDS: East African long rains Extreme wet events Rainfall variability

\section{INTRODUCTION}

The East African 'long rains' (March to May, MAM) contribute a large part (up to $45 \%$ ) of the annual rainfall over Kenya and Tanzania. Even if its interannual variability is not as large as that of the 'short rains' season (October to December, OND; Nicholson 1996) it strongly affects agricultural activities which are a major part of the gross domestic product.

Contrary to the short rains, causes of the interannual variability of the MAM rainfall amount remain largely unknown; previous studies have failed to show strong teleconnections with the El Niño Southern Oscillation (ENSO; Ogallo 1988; Ogallo et al. 1988; Hastenrath et al. 1993; Philipps and McIntyre 2000) or atmospheric and oceanic fields, such as Indian Ocean sea-surface temperature (SST; Beltrando 1990). However, Nicholson (1996), Nicholson and Kim (1997) and Indeje et al. (2000) found weak positive rainfall anomalies in the onset year of ENSO conditions, and more pronounced negative anomalies in the decaying phase of ENSO. Fundamentally, the MAM rainy season is triggered by the duration of ENSO (Camberlin and Okoola 2003) as well as by the intraseasonal activity (Okoola 1998). Each rainy season often comprises several 5- or 10-day wet events, separated by drier periods. The number and intensity of these rainy spells influence the within-season precipitation distribution, which is as important as seasonal amounts for agriculture. However, our knowledge of mechanisms causing precipitation during the long rains remains very incomplete.

The Madden-Julian Oscillation (MJO), known as the dominant mode of tropical intraseasonal climate variability (Madden and Julian 1971; 1972; 1994), has recently been shown to have a significant influence in regions hitherto considered to be away

\footnotetext{
* Corresponding author: Centre de Recherches de Climatologie, Sciences Gabriel, BP 27877, F21078 Dijon Cedex, France. e-mail: benjamin.pohl@u-bourgogne.fr
}

(c) Royal Meteorological Society, 2006. 


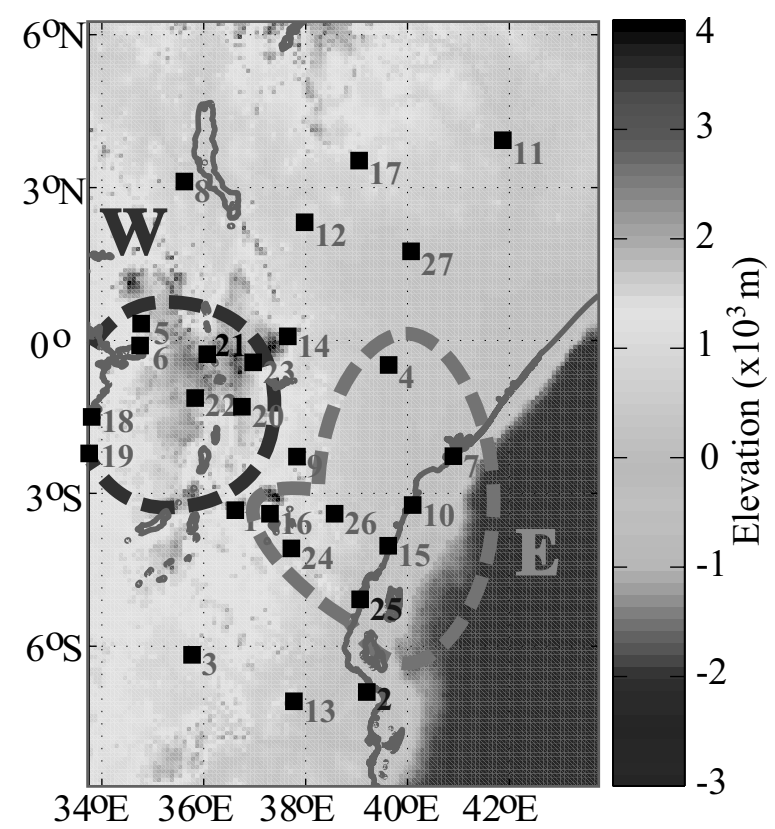

Figure 1. Kenya and northern Tanzania (EEA) topography and location of the rain-gauge stations. The coastal area $(\mathrm{E})$ and Highland area $(\mathrm{W})$ used to calculate $\mathrm{E}$ and $\mathrm{W}$ rainfall indices (see text) are delineated by dashed lines.

from core regions of MJO variability, e.g. Western Africa (Matthews 2004) and Western Asia (Barlow et al. 2005). In Equatorial East Africa (EEA, comprising Kenya and northern Tanzania) it has been found in Part I of this paper (Pohl and Camberlin 2006, hereafter PC06) that precipitation is significantly modulated by the MJO during both the MAM and OND rainy seasons. The rainfall responses are, however, spatially different. The eastern region (Kenyan coast, henceforth E, in Fig. 1) precipitation index was seen to be out of phase with the index in the western region (Highland region, henceforward W); see Fig. 1 for the locations of each region. This difference was found to reflect the influence of local topography and large-scale zonal gradients of mean sea level pressure (MSLP) between the Atlantic and Indian Ocean basins. On average, $\mathrm{E}$ experiences a rainfall peak associated with easterly advection of moisture from the Indian Ocean, corresponding to low (high) MSLP over the Atlantic (Indian) basins. By contrast, the rainiest periods in $\mathrm{W}$ seem to result from deep atmospheric convection, and a reversed anomaly of the pressure gradient between the two oceans. These opposite patterns are triggered by the MJO cycle and materialize in its opposite phases.

Following PC06, which depicted the mean influence of the MJO on East African rainfall at the pentad (5-day) time-scale, the present study focuses on the effects of the oscillation at both shorter (daily) and longer (interannual) time-scales. Only the long rains season is analysed, because this constitutes the main growing season in the region, and yet suffers from a poor understanding of the mechanisms which trigger the rains.

The modulation of extreme daily wet events by the MJO is first analysed. On the one hand, Jones et al. (2004) showed that the MJO was liable to modulate the frequency of extreme precipitation events throughout its cycle; but their study was at the global scale and cannot be directly transposed to the EEA region. On the other hand, regional studies (e.g. Okoola 1998, 1999b) have focused on heavy rainfall events affecting 
the whole EEA, but the implication of the MJO in their occurrence has never been established to date. We aim here to fill the gap between these two approaches.

This study, then, focuses on the interannual variability of the long rains; in particular, the role of the amplitude of the MJO signal is examined. The portion of the variance of daily rainfall indices that is due to the MJO is also investigated, as well as its interannual fluctuations.

\section{DATA}

Rainfall data used consist of daily rain-gauge records over the period 1971-95, obtained from the Kenyan and Tanzanian meteorological services (27 stations with fewer than $1.3 \%$ of values missing, see Fig. 1 for locations). Rainfall indices were computed for both W and E regions (Fig. 1) as the spatial average of all appropriate station data. The daily time-scale was used in this study in order to extract extreme rainfall events.

In addition the Global Precipitation Climatology Project (GPCP) dataset (Huffman et al. 1997) provides gridded satellite- and rain-gauge-derived rainfall estimates at the global scale. At the daily time-scale, the dataset of the National Oceanic and Atmospheric Administration comprising outgoing long-wave radiation (OLR; Liebmann and Smith 1996) is used as an estimator of deep tropical convection.

Atmospheric fields (i.e. vertical velocity $(w)$, zonal $(u)$ and meridional $(v)$ wind components, temperature $(T)$, relative humidity $(r h)$ ) are from the National Centers for Environmental Prediction (NCEP)-DOE AMIP II R-2 re-analysis (Kanamitsu et al. 2002). The dataset is an update of the NCEP-National Center for Atmospheric Research (NCAR) re-analysis (Kalnay et al. 1996), featuring newer physics and observed soil moisture forcing, and eliminates several previous errors; it is available at the daily time-scale since January 1979. Among these fields, $u, v$ and $T$ are considered as 'most reliable' since they strongly depend on instrumental measurements; $w$ and $r h$ are considered to be 'quite reliable' because they rely more on the general circulation model parametrization. Specific humidity $(Q)$ was calculated using the Goff-Gratch equation (Goff and Gratch 1946).

The MJO signal was extracted using the two daily indices, RMM1 and RMM2, developed by Wheeler and Hendon (2004, hereafter WH04). Presentations of the indices and composite maps can be found in WH04 and PC06.

\section{Results}

(a) Abnormally wet events at the daily time-scale

The role of the MJO in the occurrence of extreme wet events over EEA is investigated in this section. Since the area is not homogeneous as far as intraseasonal variability is concerned, the same two sub-regions (E and W, Fig. 1) defined in PC06 are analysed separately. Daily rainfall anomalies for each regional index are calculated after removal of the annual cycle, the latter being averaged on the MAM 1979-95 period. These years correspond to the longest common period of availability of the NCEP-2 re-analysis and daily precipitation data. The extreme wet anomalies are then isolated using the percentile method, and the highest $5 \%$ of values are retained. As an indication, and since the extreme rainfall events are extracted after removal of the annual cycle, they correspond to daily rainfall amounts above $\sim 20 \mathrm{~mm}$ in the Highland (W) region in early March, $\sim 29 \mathrm{~mm}$ in mid-April and $\sim 25 \mathrm{~mm}$ in late May. 

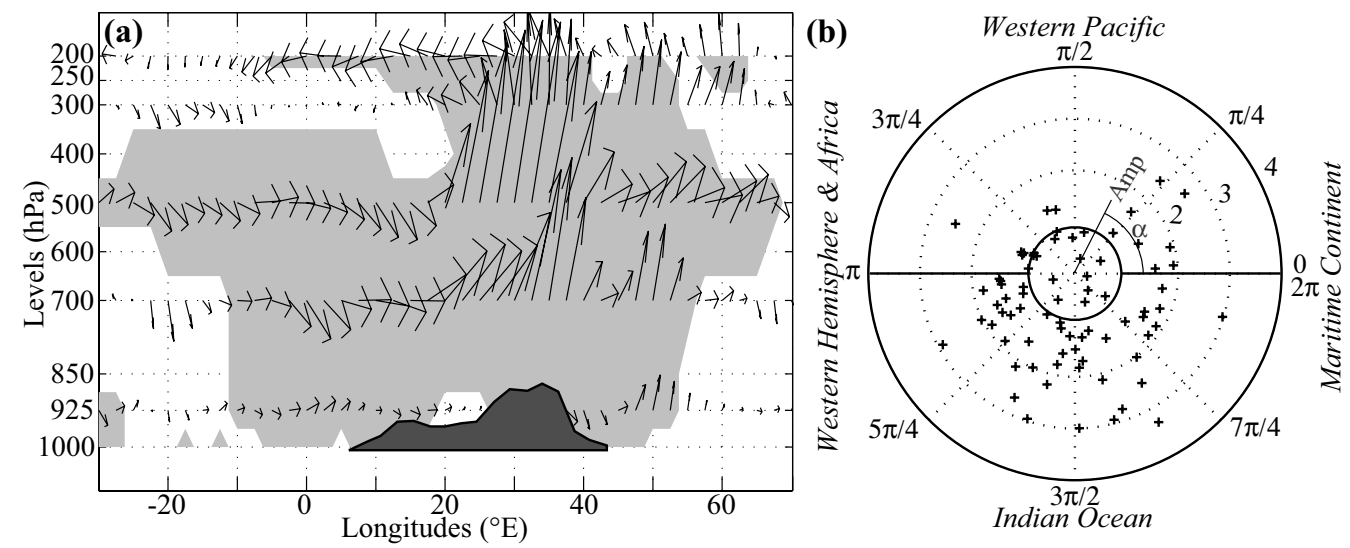

Figure 2. (a) Vertical cross-section of the atmosphere along the equator $\left(2.5^{\circ} \mathrm{N}-2.5^{\circ} \mathrm{S}\right)$ during extreme daily rainfall events in the EEA Highlands. Significant anomalies are shaded (Hotelling $t^{2}$-test, 95\% level). The topography of the African continent along the equator as it appears in the NCEP spectral model is also shown. (b) Distribution of the daily rainfall events (crosses) with respect to the MJO phase, $\alpha$. The estimated location of the enhanced convective signal related to the MJO is labelled. The inner circle encompasses rainfall events occurring at times of weak MJO activity (amplitude $<0.9$ ). See text for further details.

Composite atmospheric patterns corresponding to these rainfall events are examined, using similarly deseasonalized data. Figure 2(a) represents a vertical crosssection of the troposphere along the equator associated with the extreme rainfall events over the $\mathrm{W}$ region. The Hotelling $t^{2}$-test, used to determine the significance of the anomalies, is the multivariate generalization of the $t$-test; in the present case it is applied to the zonal $(u)$ and vertical $(w)$ components of the wind. Figure 2(b) presents the MJO phases at which the rainfall events occur. Following WH04, the use of polar coordinates, where each point is defined by a distance and an angle measurement, is possible because the two indices used to monitor the MJO are in quadrature. The distance is interpreted as the amplitude of the MJO signal ('Amp' in Fig. 2(b)) while the angle $\alpha$ depicts the corresponding phase of the oscillation, approximately corresponding to the location of the MJO-induced anomalies in atmospheric convection and circulation. Additional details are given in PC06.

Heavy rainfall in W clearly results from deep convection (Fig. 2(a)), and ascending motion anomalies are observed above the EEA Highlands from 700 to $200 \mathrm{hPa}$. In the lower troposphere, zonal westerly anomalies may be interpreted as moisture advection from the Congo basin. This result is consistent with the empirically observed role of lower-layer westerly bursts in rainfall enhancement over East Africa (Johnson and Mörth 1960; Nakamura 1968; Camberlin and Wairoto 1997). Thompson (1957), Griffiths (1959) and Trewartha (1961) suggested that these wet spells were triggered by incursions of the humid unstable westerly Congo air stream. Interestingly this atmospheric configuration also resembles the local anomalies generated at a given phase of the MJO, particularly seen to involve rains over the $\mathrm{W}$ region of EEA (PC06). At this time of the cycle the large-scale zonal gradient in lower-level pressure between the Atlantic and Indian Oceans favours the establishment of such westerly anomalies over equatorial Africa (PC06).

Indeed, Fig. 2(b) shows that most very wet days over the Highlands are preferentially concentrated in particular phases of the MJO. The events occurring when the 


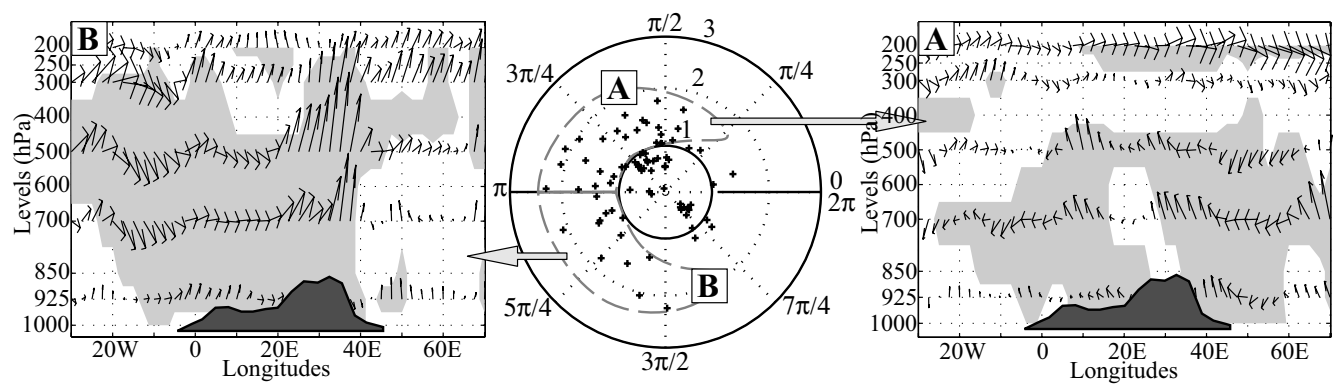

Figure 3. As Fig. 2 but for extreme daily rainfall events in the coastal region (E, see text).

MJO amplitude is less than 0.9 (21\% of the sample) should be interpreted as independent of the MJO itself, the signal of the oscillation at these times being very weak. However, the remaining events are visibly concentrated in the second half of the MJO cycle (centred on phase $3 \pi / 2$ ) with $62 \%$ of the overall sample. This confirms that the previously described atmospheric pattern (Fig. 2(a)) is clearly modulated by the MJO, its occurrence not being homogeneously distributed over the cycle. At this time during the oscillation the main convective clusters are located in the Indian Ocean basin, which is consistent with the delayed convection over the East African Highlands observed in PC06.

Figure 3 presents the same analysis applied to the E region index. In this case $28 \%$ of the events are found at times of weak MJO signal amplitude. The remaining points $(72 \%)$ are concentrated in the half-cycle extending from $\pi / 2$ to $3 \pi / 2$, while the results concerning this index conclude with a rainfall peak occurring from $\pi / 2$ to $\pi$ (PC06). The fact that several extreme wet events are found at phases that are on average associated with drier conditions ( $\pi$ to $3 \pi / 2$; see PC06) needs to be examined. Therefore, the sample is divided into two distinct groups, labelled A and B in Fig. 3.

Most of these events (group A, representing $48 \%$ of the overall sample) occur between phases $\pi / 2$ and $\pi$, i.e. the peak of rainfall associated with the MJO in the $\mathrm{E}$ region (PC06). They are concomitant with low- to mid-tropospheric easterly anomalies along the equator. The air flow is then forced to ascend the eastern slopes of the East African Highlands, and westerly anomalies are found in the upper layers. These wet events in the east, which seem to result from enhanced moisture advection from the Indian Ocean, clearly occur when dry conditions prevail in $\mathrm{W}$, illustrating the frequent out-of-phase variability of the rains in the two regions and its relationship with MJO activity (PC06). However, some wet events in E also occur at phases between $\pi$ and $3 \pi / 2$ (group B, $20 \%$ of the sample, see Fig. 3). The corresponding circulation anomalies reveal a pattern resembling that shown for the W region (Fig. 2(a)). In such cases, deep convective clusters developed over the Highlands are hypothesized to extend eastwards over the coastal plains and generate abnormally abundant rainfall there. At these times the $\mathrm{E}$ and $\mathrm{W}$ rainfall indices are in phase.

Two major deductions may then be formulated:

- The influence of the MJO on the occurrence of EEA wet spells is confirmed, and it extends to the daily time-scale and includes the most extreme events.

- It is also confirmed that the EEA region is not homogeneous as far as the rainfall field is concerned, possibly associated with the location of the inter-oceanic confluence. Highland extreme rainfall mainly originates from moisture advection from the Congo basin and subsequent deep convection (consistent with PC06); the coastal 
TABLE 1. COMMON VARIANCE (\%) BETWEEN THE MADDEN-JULIAN OSCILLATION AND RAINFALL IN THE WEST (HIGHLAND) REGION OF EQUATORIAL EAST AFRICA AT INTRASEASONAL TIME-SCALES FOR MARCH TO MAY OF EACH YEAR OVER THE PERIOD 1979-95

\begin{tabular}{lccccccccr}
\hline Year & 79 & 80 & 81 & 82 & 83 & 84 & 85 & 86 \\
\hline No filter & $\mathbf{1 2 . 3}$ & $\mathbf{2 8 . 1}$ & $\mathbf{2 3 . 0}$ & 2.2 & $\mathbf{1 3 . 7}$ & $\mathbf{1 9 . 2}$ & $\mathbf{1 7 . 1}$ & $\mathbf{2 3 . 4}$ \\
5-day low-pass & $\mathbf{3 2 . 2}$ & $\mathbf{5 2 . 3}$ & $\mathbf{4 5 . 5}$ & 4.6 & 28.9 & $\mathbf{3 5 . 3}$ & $\mathbf{3 0 . 2}$ & $\mathbf{4 5 . 9}$ \\
20-day low-pass & 44.3 & $\mathbf{7 1 . 9}$ & $\mathbf{6 2 . 1}$ & 11.8 & $\mathbf{5 9 . 8}$ & $\mathbf{6 9 . 1}$ & $\mathbf{4 9 . 5}$ & $\mathbf{8 0 . 2}$ \\
& & & & & & & & & \\
\hline Year & 87 & 88 & 89 & 90 & 91 & 92 & 93 & 94 & 95 \\
\hline No filter & $\mathbf{1 9 . 2}$ & $\mathbf{2 7 . 0}$ & $\mathbf{2 0 . 0}$ & 8.9 & 12.3 & 5.5 & 5.1 & 8.9 & 8.3 \\
5-day low-pass & $\mathbf{3 5 . 1}$ & $\mathbf{5 3 . 0}$ & $\mathbf{4 7 . 0}$ & 17.3 & 22.1 & 9.2 & 12.9 & 15.0 & 15.2 \\
20-day low-pass & $\mathbf{5 3 . 6}$ & $\mathbf{7 8 . 0}$ & $\mathbf{7 6 . 0}$ & 27.3 & $\mathbf{3 8 . 9}$ & 20.5 & 22.1 & 21.6 & 33.2 \\
\hline
\end{tabular}

Significant correlation values (Bravais-Pearson test, 95\% level) are in bold. The reduced numbers of degrees of freedom due to autocorrelation and filtering have been considered when testing significance (Der Mégréditchian 1992). Shading denotes 'high- $r^{2}$ ' seasons; other years are 'low- $r^{2}$ ' years (see text).

plains experience rain spells resulting from enhanced moisture advection from the equatorial Indian Ocean forced to ascend by the East African topography, and also convective precipitation extending eastwards from the Highlands. The contribution of such extreme events to the interannual variability of the long rains is examined in subsection 3(c).

\section{(b) Interannual modulation in the MJO influence on intraseasonal rainfall variability}

Here we consider not only the wettest events but also the overall common variance between the rainfall series and the MJO. Both unfiltered and low-pass filtered rainfall indices (5- and 20-day) are considered after removal of the annual cycle. The series are then correlated year by year with the two MJO indices (RMM1 and RMM2). The rain and MJO time series are lagged (by \pm 15 days, approximately half an MJO cycle) and the common variance (Table 1) is taken as the highest determination coefficient, $r^{2}$, for all lags (i.e. from -15 to +15 days) and for either of the two RMM indices. This takes into account possible delays in the rainfall response to the MJO, as well as the non-stationarity of the temporal period of the oscillation. As an alternative method, $r^{2}$ values of the multiple linear regression between rainfall and the two RMM indices were computed with no lag. The two methods enabled us to rank years with respect to the influence of the MJO on intraseasonal rainfall variability. Quite similar results were obtained for the $\mathrm{W}$ region, but not for the $\mathrm{E}$ region. This is suspected to be related to the fact that, as shown in subsection 3(a), rainy events can be recorded at various phases of the cycle depending on which MJO event is analysed, denoting different rainfall mechanisms. Therefore, the analyses are restricted to the $\mathrm{W}$ index which displays a constant phase-locking with the MJO.

It is first seen that for 10 out of 17 years even the daily (unfiltered) rainfall time series are significantly correlated with the MJO (Table 1). However, the common variance varies greatly from year to year, ranging from $2.2 \%$ to $28.1 \%$. Although it is statistically significant on average (PC06), the effect of the MJO on East African rainfall is not permanent. The percentage of common variance is enhanced when the rain series are filtered. It ranges from 5\% to 53\% with a 5-day low-pass filter. A 20-day filter further enhances the common variance by forcing the two signals to vary at comparable time-scales. Sometimes considerable increases in the variance are explained (e.g. in $199533 \%$ for the 20-day low-pass filtered index, as compared to 8.3\% for the unfiltered data). These differences show that high-frequency rainfall variability, 


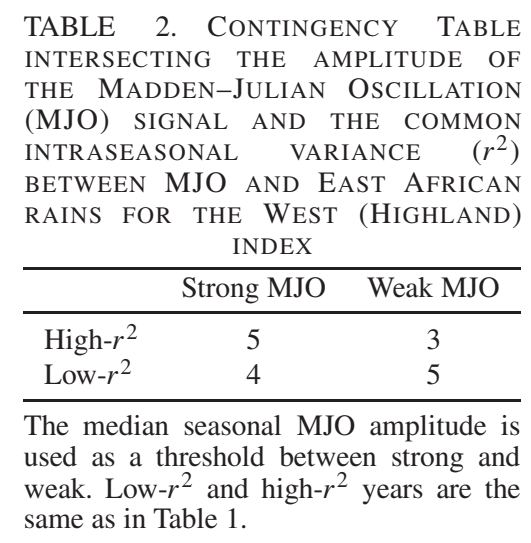

leading to short-lived wet events occurring at various MJO phases, sometimes obscures the relationship between the MJO and rainfall. There also remain some seasons for which the low-frequency intraseasonal rainfall variability exhibits little dependency on the MJO (e.g. 1982, 1990, and 1992 to 1995).

What are the reasons behind these interannual changes in the relationship between MJO and intraseasonal rainfall distribution in EEA? To answer this question, composite analyses are applied which isolate the seasons during which the MJO strongly affects the EEA rainfall distribution (i.e. 'high $-r^{2}$ years') from the other seasons (i.e. 'low$r^{2}$ years'). The sample was defined on the basis of the significance of the correlations between raw rainfall series and the RMM1 and RMM2 MJO indices. The years that were retained are those shaded in Table 1.

A first potential candidate to explain the inconstancy of the MJO-EEA rainfall relationship is the intrinsic amplitude of the MJO signal; a stronger relationship might be expected in high-amplitude MJO years. To test this the years are separated into two groups: 'strong MJO' for the seasons with seasonal mean MJO amplitudes over the median value (1.00) and 'weak MJO' encompassing all other seasons. However, the contingency table intersecting these years and the high- and low- $r^{2}$ years for the $\mathrm{W}$ region (Table 2) reveals an independence between the MJO amplitude and the common MJO-rainfall variance. This suggests that external climatic forcings may be involved instead.

Seasonal means of SST (Reynolds et al. 2002), $u$ and $v$ wind fields at 850 and $200 \mathrm{hPa}$, geopotential height, velocity potential, specific- and relative humidity, moist static energy (MSE) vertical distribution and OLR were then composited with respect to high $-r^{2}$ and low- $r^{2}$ years in regard to EEA rainfall. None of them exhibits any significant difference between the two groups of years. However, this absence of significant signals in the seasonal means may conceal contrasting patterns at different phases of the MJO cycle. A second analysis discriminated between different phases of the MJO cycles, separated into low- $r^{2}$ and high- $r^{2}$ seasons. At given phases of the oscillation, vertical gradients of MSE (calculated with temperature, geopotential height and specific humidity as input variables) exhibit significant differences between the two samples. The interannual differences are particularly marked at the MJO phases bringing rainfall over the region (i.e. $3 \pi / 2$, PC06).

Figure 4 shows the MSE differences between high- $r^{2}$ and low- $r^{2}$ years, for a tropospheric cross-section along the equator, during the MJO phase $5 \pi / 4$ to $7 \pi / 4$ (wet in W). It may be recalled that during this phase the main convective clusters 


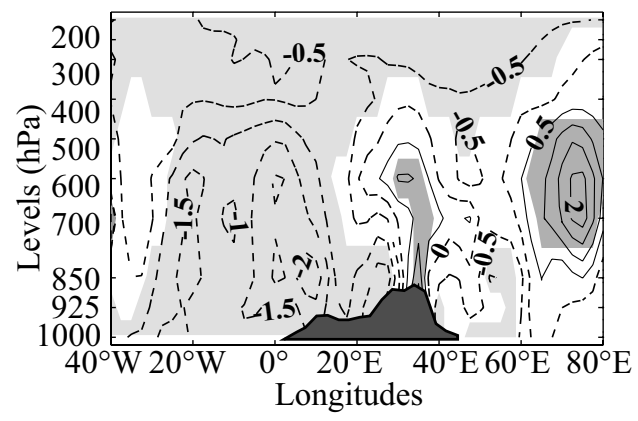

Figure 4. Difference of Moist Static Energy along the equator $\left(2.5^{\circ} \mathrm{N}\right.$ to $\left.2.5^{\circ} \mathrm{S}\right)$ between 'high- $r^{2}$, and 'low- $r^{2}$, years (as defined in Table 1) with respect to the West region rainfall index, during the MJO phase $5 \pi / 4$ to $7 \pi / 4$. Significant positive (negative) differences ( $t$-test, 95\% level) are shaded dark-grey (light-grey). See text for details.

associated with the MJO (see locations in Fig. 2(b)) first reach East Africa (from $5 \pi / 4$ to $3 \pi / 2$ ) and then shift to the Indian Ocean (from $3 \pi / 2$ to $7 \pi / 4$ ). Following PC06, convective clusters remain active at this time over the EEA Highlands.

Over EEA, significantly lower values of MSE are recorded in upper layers (400$200 \mathrm{hPa}$ ) during the years presenting the highest common variance between the MJO and the precipitation indices (Fig. 4) compared with other years. Similar results are found for the Atlantic Ocean and Congo basin, over the whole depth of the troposphere. Separate analyses of the different input fields listed above show that the significant differences observed in Fig. 4 denote a strong cooling of the upper troposphere over Eastern Africa, corresponding with abnormally low 400 to $200 \mathrm{hPa}$ geopotential heights. Such negative anomalies immediately below the tropopause are expected to trigger deep convection. This is confirmed by the OLR anomalies, which also present significantly lower values during the $5 \pi / 4$ to $7 \pi / 4$ phases of high- $r^{2}$ seasons. A moderate cooling of the air masses is also found in the whole troposphere over and around the equatorial Atlantic. In the lower layers it corresponds to significant positive geopotential height anomalies, especially over the Congo basin. Such a pattern is hypothesized to favour lower-level eastwards moisture fluxes to East Africa, in accordance with what was shown in PC06, although cooler air masses also have a slightly reduced hygrometric capacity.

At these phases of the MJO cycle, upper-tropospheric temperature anomalies at $250 \mathrm{hPa}$ (see Fig. 5) are very small over the EEA region. They tend to become significantly negative after phase $3 \pi / 2$, while the main convective clusters associated with the MJO reach the Equatorial Indian Ocean in relation with this upper-layer cooling. More generally, air temperature anomalies exhibit a strong and significant propagative signal that can be found within the whole tropical belt; several studies suggest that it is mostly related to Kelvin-Rossby wave conditional instability of the second kind. For instance, Matthews (2000) depicted a 'cool' eastward Kelvin wave and a 'warm' westward Rossby wave completing a circuit along the equator and meeting 20 days later above West Africa; Hsu and Lee (2005) described this propagation as three consecutive Kelvin waves relaying the signal in the Indian, Pacific and Atlantic ocean basins in relationship with the surface topography. In the present case, the negative temperatures occurring from phase $5 \pi / 4$ to phase $7 \pi / 4$ (Fig. 4 ) denote an anomalously early cooling of the upper troposphere on the East African meridian (Fig. 5). The negative temperature anomalies then rapidly dissipate during the following MJO phases (not shown). These observations suggest that tropical upper-tropospheric 


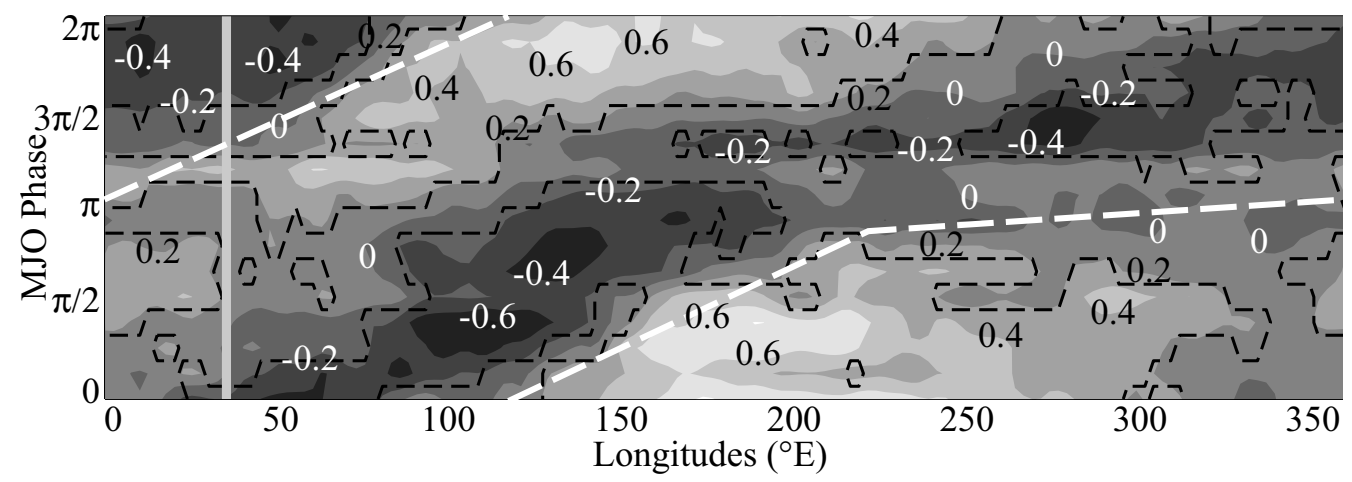

Figure 5. Madden-Julian Oscillation (MJO) phase-longitude diagram of air temperature anomalies (K) over the MJO cycle at $250 \mathrm{hPa}$. The period of analysis is months March/April/May from 1979 to 1995. Dashed black lines emphasize significant anomalies ( $t$-test, $95 \%$ level). The East African meridian is shown (solid grey line) as well as the estimated location of MJO-related enhanced convection within the Tropics (dashed white lines).

dynamics are a key feature for the temporal alternation of wet and dry spells in the Highlands region.

\section{(c) MJO influence on MAM rainfall interannual variability}

The previous section emphasized the significant, yet interannually fluctuating, relationship between intraseasonal rainfall variations and the MJO. However, MAM total seasonal rainfall also fluctuates substantially from year to year, and it may be questioned to what extent this interannual variability is related to MJO activity. To test this, 3-month rainfall amounts in the East African E and W regions were computed over the period 1979-95 in order to obtain purely interannual time series. The variability of the onset and cessation dates of the long rains as well as that of the season duration are all examined. These dates were obtained using a method developed by Camberlin and Diop (2002); here it is applied to the entire EEA region, i.e. all the 27 rain-gauge stations shown in Fig. 1. Additionally, the fluctuations in the total MAM number of extreme wet events (as defined in subsection 3(a)) in both the Coast (E) and Highland (W) sub-regions (Fig. 1) are considered. All these series are then correlated with the mean seasonal MJO amplitude, and with two indices representative of large-scale climate modes known to trigger interannual variability in the Indian Ocean basin, namely: the Southern Oscillation Index (SOI) depicting ENSO, and the 'Dipole Mode Index' (DMI, Saji et al. 1999) depicting Indian Ocean zonal SST gradients. The results are presented in a correlation matrix (Table 3), which aims at addressing two issues:

- How is the seasonal rainfall amount related to the various characteristics of the rainy season (e.g. onset, frequency of extreme events), and how does it relate to the MJO activity?

- What is the part played by global/regional modes of climate variability?

(i) Relation of seasonal rainfall total to other characteristics and the MJO. In the EEA region as a whole the role of the onset date (i.e. interannual fluctuations in the beginning date of the rainy season) on the seasonal amount is greater than that of the cessation date (Table 3), which confirms the results of Camberlin and Okoola (2003). Interestingly, the coastal region rainfall seems to be much more dependent on the cessation date. This can be explained by the higher late-season (May) rainfall amounts over this area (24\% of the annual amount on average, versus $12 \%$ for the Highlands). On the other 


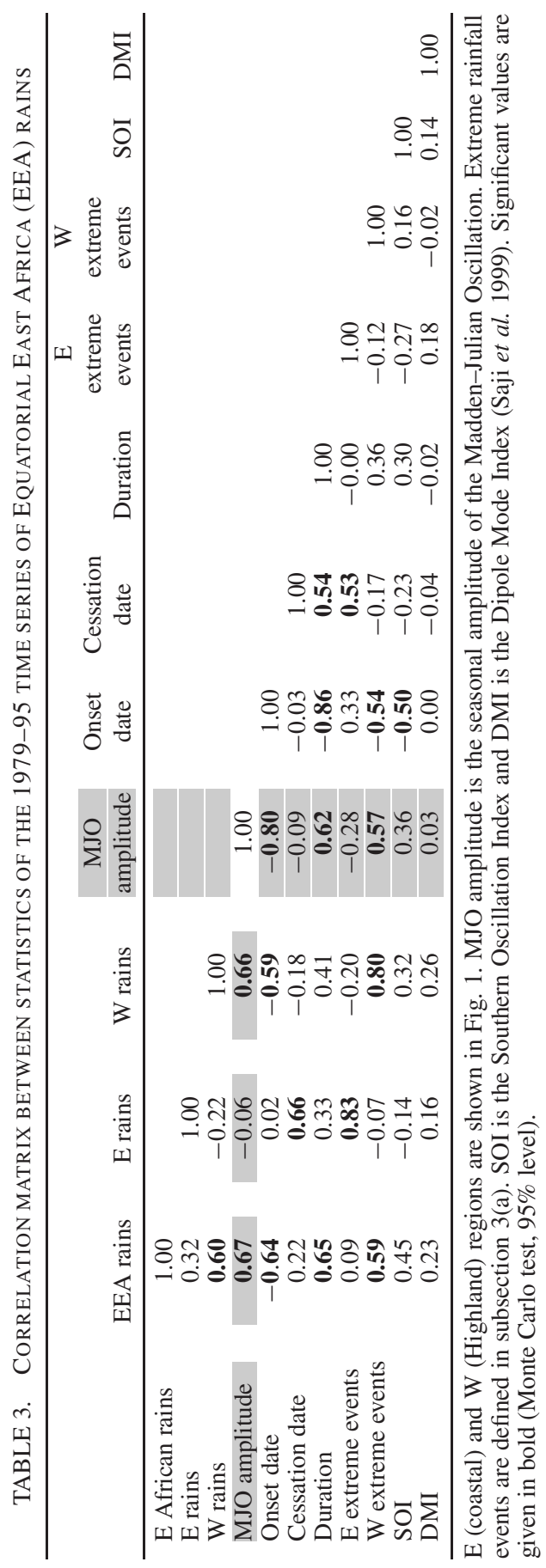




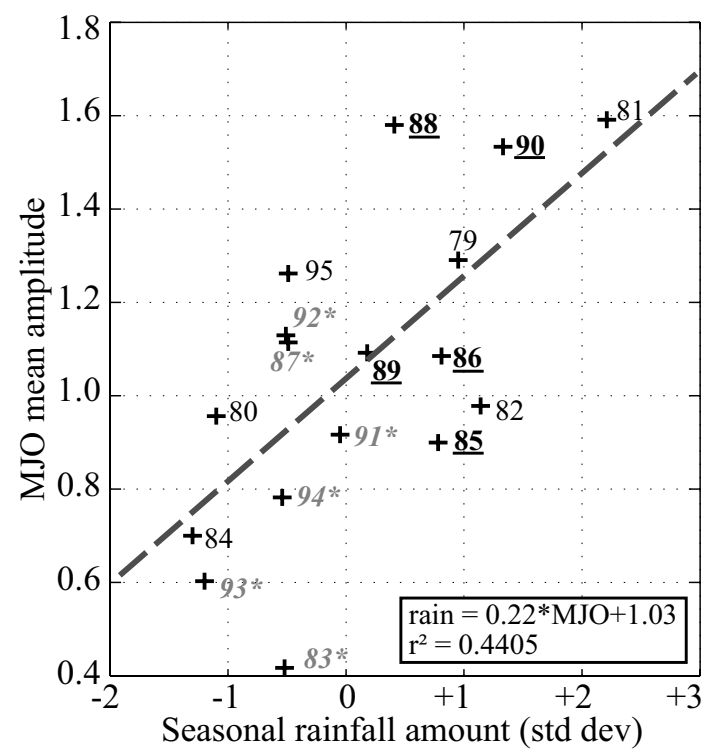

Figure 6. Scatter plot of seasonal rainfall amount and seasonal Madden-Julian Oscillation (MJO) amplitude. The linear regression equation and the coefficient of determination are indicated. The six lowest Southern Oscillation Index (SOI) seasons are marked with an asterisk and in italic, the five highest SOI seasons are underlined and in bold.

hand the $\mathrm{W}$ index depends more strongly on the onset date, generally occurring in March (10\% of the annual amount for the Highlands, versus $7 \%$ for the Coast). Both E and W total rainfall amounts strongly depend on the number of extreme wet events during the long rains $(r \approx 0.8)$. The East African rainfall index variations are also seen to be more representative of the fluctuations observed in the Highlands than on the coast.

Table 3 also documents the possible implication of the MJO in the long rains interannual variability and fluctuations of the onset date. It is found that the mean MAM amplitude of the MJO signal is significantly and highly correlated with the onset date (64\% of variance explained, Table 3) as well as to a lesser extent with the duration of the rainy season. Lagged correlations between the February MJO amplitude and the onset date (not shown), however, reveal no significant relations, which rules out MJO amplitude as an onset predictor. The seasonal precipitation amount in the EEA region is also significantly correlated with the seasonal MJO mean amplitude ( $r=0.67$; Fig. 6$)$. Except in the coastal region (Table 3), the long rains are greater and the onset is earlier in years displaying a larger MJO signal amplitude.

These correlations are, however, obtained over a rather short time series (17 years). To assess the temporal stability of these relationships we use additional datasets which extend over longer periods (1948-2000). From 114 monthly rain-gauge stations over Kenya and Tanzania, new EEA, E and $\mathrm{W}$ rainfall indices are computed as averages using 114, 23 and 16 stations, respectively. For the $\mathrm{E}$ and $\mathrm{W}$ indices, only the stations included in the regions delineated in Fig. 1 are retained, for consistency with the remainder of the paper. Daily MJO indices are computed over the 1948-2005 period from NCEP-1 re-analyses (Kalnay et al. 1996). The same methodology as that of WHO4 is used, except that the OLR field is excluded in order to extend the analysis to years prior to 1974. An empirical orthogonal function analysis is thus performed on the 20- to 75-day filtered zonal wind field at 850 and $200 \mathrm{hPa}$, after removal of the annual cycle, and the 


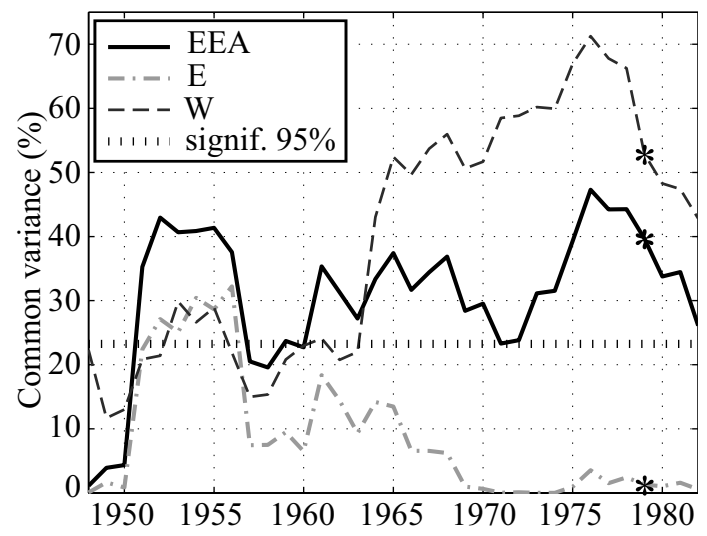

Figure 7. Percentage of common variance $\left(r^{2}\right)$ between the Madden-Julian Oscillation (MJO) seasonal amplitude and the seasonal rainfall amount for Equatorial East African (EEA) coastal (E) and Highland (W) indices, calculated on a 17-year moving window. The year labelled on the $x$-axis corresponds to the first year of the moving window. The 95\% significance level for the corresponding correlation values is shown by the straight dashed line. Asterisks show the period 1979-95.

area between $15^{\circ} \mathrm{N}$ and $15^{\circ} \mathrm{S}$. The first two principal components, explaining 12.6 and $10.2 \%$ of the initial variance, respectively, are in quadrature and thus depict the wellknown mean eastward propagation of the MJO. The resulting MJO indices are then compared to those of WH04 over their common period of availability (i.e. 1974-2005). For the MAM season, for instance, the seasonal mean MJO amplitude shows $94 \%$ of common variance between the two datasets. The NCEP-derived indices are, therefore, judged as reliable for the last 30 years. Before 1974 they depend on the quality of the re-analyses, as discussed in Poccard et al. (2000) over the African domain, Trenberth (2001) and Kinter et al. (2004), but being a global signal by nature, the MJO is thought to be weakly sensitive to regional-scale biases in the data.

Correlations between the MAM seasonal amount and the amplitude of the MJO signal are then calculated on 17-year moving windows, to allow comparison with Table 3. The results are shown in Fig. 7. For the 1979-95 period discussed above, consistent results are found between the different datasets for the EEA, E and W indices. With the new rainfall and MJO indices, the common variance between the MJO amplitude and rainfall changes from 44 to $40 \%$ for EEA, from 44 to $53 \%$ for the Highlands, and remains close to zero for the coast. The correlations are constantly above the 95\% significance level from the mid-1960s to the end of the period, for the EEA and $\mathrm{W}$ indices. The variance explained by the MJO amplitude generally fluctuates between 30 and $45 \%$ for EEA (50 to $70 \%$ for the Highlands). Insignificant correlations are, however, found on the coast (common variance below 10\%) in agreement with Table 3. The sudden increase in the correlation values in the mid-1960s may either be attributed to inter-decadal fluctuations or to the lower reliability of the re-analyses over this period. Nonetheless, the role of the MJO on the long rains interannual variability is confirmed, and extended back to the mid-1960s.

In order to emphasize the incidence of the MJO amplitude on the long rains onset date and interannual variability, Fig. 8 displays the mean rainfall distribution (smoothed by a low-pass filter to eliminate individual events) during the strongest and weakest $\mathrm{MJO}$ years for the $\mathrm{E}$ and $\mathrm{W}$ regional indices. The rainy seasons occurring under strong MJO conditions exhibit higher amounts in the first half of the period (March and early April). The difference between the strongest and weakest years is very obvious for 


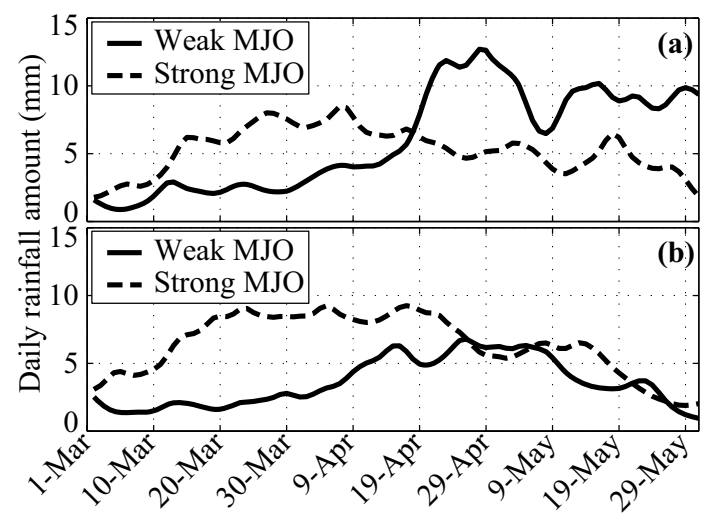

Figure 8. Daily rainfall distribution in Equatorial East Africa during the 3 years with the weakest (1983, 1984, 1993 ) and the strongest $(1981,1988,1990)$ Madden-Julian Oscillation (MJO) activity in the period 1979-95, for: (a) the coastal (E) index, and (b) the Highland index (W). The time series have been smoothed using a Butterworth 20-day low-pass filter in order to improve the readability.

the Highlands. Over EEA as a whole the rainy season tends to start earlier during strong MJO years, in accordance with the very high correlation between the onset date and the MJO amplitude noted in Table 3. Higher seasonal amounts are thus recorded since the rainy period is longer.

Whereas the OND short rains are strongly correlated with large-scale SST patterns (Beltrando and Cadet 1990; Beltrando and Duchiron 1996; Black et al. 2003) the mechanisms that trigger the fluctuations in the MAM precipitation amounts are still largely unknown, and no clear large-scale teleconnections have been found (Ogallo et al. 1988; Camberlin and Philippon 2002). It is here hypothesized that the weakness of the interannual teleconnection signals for the long rains seasonal amounts has its origin in the fact that the MJO interferes at the intraseasonal time-scale with interannual signals. Over the EEA region during the boreal spring season, the intraseasonal oscillation quasi-periodically generates the conditions leading to abnormally wet events. The correlation between the seasonal amount and the MJO amplitude being positive, strong MJO activity is seen to favour abundant rainfall, and the effects of the active convection phases on the rainfall field are finally greater than those of the suppressed convection phases. In other words, the MJO quasi-periodically 'adds' rainfall to the long rains, rather than simply enhancing the intraseasonal oscillations between dry and wet spells. These statements seem particularly true for the first half of the rainy season.

(ii) Relation of seasonal rainfall to global/regional modes of climate variability. As noted in earlier studies, Table 3 shows that ENSO and the Indian Ocean zonal mode do not play a significant role in the EEA long rains; they are also statistically unrelated to the MJO amplitude. However, Camberlin and Philippon (2002) showed that abnormally dry MAM seasons tend to be slightly more frequent over EEA when warm conditions prevail in the Equatorial Pacific. This relation was seen to be significant only in inland parts of Kenya and Uganda, i.e. roughly the area corresponding to the $\mathrm{W}$ index. The physical processes involved were not fully established.

The years with the lowest SOI values (25th percentile, in the period 1979-95) are marked with an asterisk in Fig. 6. It is quite unambiguous that they coincide with low MJO activity and also with some of the driest Long Rain seasons. Even if the amplitude of the MJO signal and ENSO do not exhibit major interactions (as shown in Table 3 and 


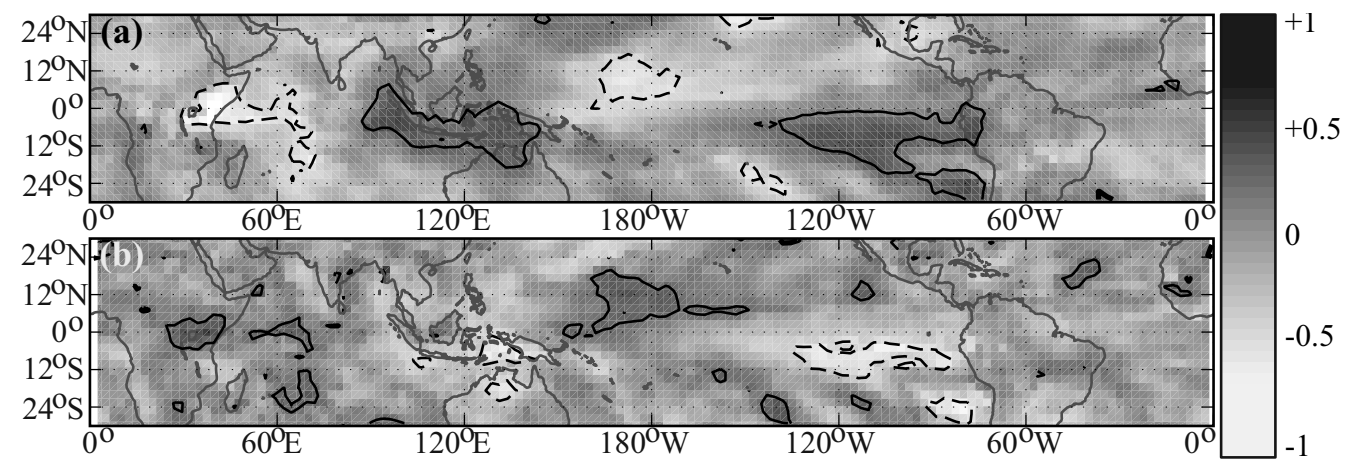

Figure 9. Correlation maps between March/April/May interannual variations of the Madden-Julian Oscillation amplitude and: (a) outgoing long-wave radiation deseasonalized anomalies, (b) Global Precipitation Climatology Project estimated rainfall amounts. The period of analysis is 1979-2001. Positive (negative) significant correlations (Bravais-Pearson test, 95\% level) are contoured with solid (dashed) lines.

by Slingo et al. (1999) and Kessler (2001)) it is suggested by Kessler that the MJO is less active over the Indian Ocean during the height of warm ENSO events—and more active over the Central Pacific Ocean, probably in connection with the eastward shift of the warm pool. It is noticeable (Fig. 6) that whereas low SOI seasons are concomitant with low MJO activity, the reverse situation is less obvious (i.e. strong MJO activity during La Niña years), which explains why the correlation between the SOI and the MJO activity is not significant. The use of other ENSO indicators (e.g. Niño3.4*) leads to similar conclusions. These results suggest that the processes leading to drier conditions in EEA during the boreal springs succeeding El Niño years are triggered by the weaker MJO intraseasonal activity of these years. Two very dry and weak MJO years, 1984 and 1980, appear as noticeable exceptions (Okoola 1998, 1999a).

Is the relationship between MJO activity and MAM rainfall amount restricted to East Africa? Figure 9 presents maps of the correlations between the MJO signal amplitude and OLR anomalies (Fig. 9(a)), and GPCP-estimated rainfall anomalies (Fig. 9(b)). Schematically, two zonal opposites appear in the Indian and Pacific Ocean basins: convection and rainfall are enhanced (inhibited) in the west (east) of the ocean basins during springs which show a strong MJO activity. The reverse situation is observed during seasons of weak MJO activity.

In agreement with the above findings, convection and precipitation appear to be significantly triggered by the MJO amplitude. The global patterns may be explained by the role of the strong ENSO events, characterized by relatively weak MJO activity (Fig. 6) and impacting on OLR anomalies over the Pacific Ocean (i.e. convection clusters shifting eastward during a warm event). Over the Indian Ocean a zonal opposition is also found, though the DMI (Saji et al. 1999) remains statistically independent of the MJO activity (Table 3).

It may finally be concluded that the seasonal intensity of the MJO significantly triggers the 3-month precipitation amount of the East African long rains. The signal is consistent spatially. The MJO effect on the MAM rainfall interannual variability is mainly through the duration of the rainy season (earlier onset date); secondly, it is through the number of extreme daily wet spells, which are more likely to occur during earlier rainy seasons (which also correspond to the strongest MJO years). At this time

${ }^{*}$ The mean SST within the area $170^{\circ} \mathrm{W}-120^{\circ} \mathrm{W}, 5^{\circ} \mathrm{S}-5^{\circ} \mathrm{N}$. 
(a)

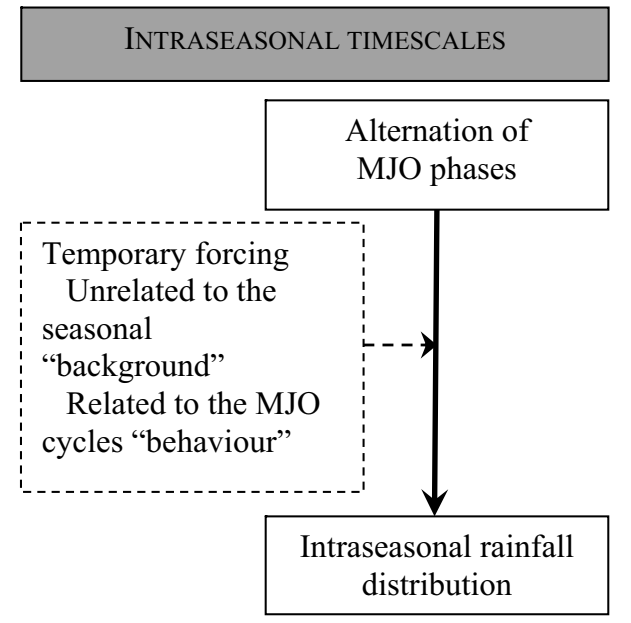

(b)

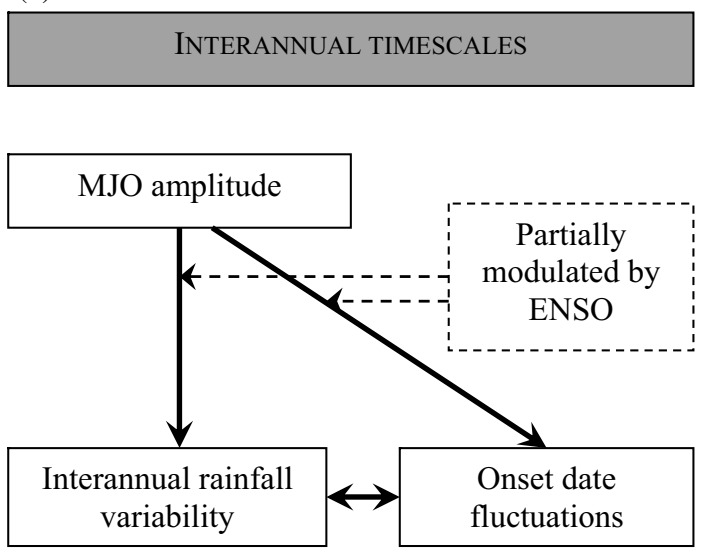

Figure 10. Summary of the relationships between East African long rains and the Madden-Julian Oscillation (MJO): (a) intraseasonal rainfall distribution, (b) interannual variability of March/April/May (MAM) rainfall amount. Dashed arrows denote recurrent modulations of the relationships at both time-scales.

of the year ENSO is seen to have a moderate impact on inland EEA rainfall variability. It is suggested that MJO activity is not fully independent of ENSO and is involved in the teleconnection.

\section{CONCLUSION}

Figure 10 summarizes the main results concerning the daily to interannual modulation of the East African long rains by the MJO.

(i) At daily to intraseasonal time-scales the alternation of wet and dry spells over EEA is significantly modulated by the current phase of the MJO, as shown in PC06. The daily extreme rainfall events (the 5\% highest rainfall anomalies after removal of the annual cycle) are also recorded during favourable phases of the intraseasonal cycle. In the Highlands region, $78 \%$ (22\%) of the very wet days fall in the second (first) half of the cycle in moderate-to-high-amplitude MJO years. As found in other parts of the world (e.g. Wheeler and McBride (2005) for Australia), the forcing is, however, not constant, and the common variance between the 5-day low-pass filtered rainfall time series and the MJO indices varies between 5\% and 53\% from year to year over the period 1979-95. The processes that modulate the influence of the MJO on the intraseasonal distribution of rainfall are independent from interannual anomalies of the seasonal climate background (e.g. large-scale atmospheric and oceanic fields such as SST, air moisture, geopotential height, etc.). Rather they involve the 'behaviour' of the $\mathrm{MJO}$, and especially the phase at which the upper-tropospheric cooling related to the eastward propagative 'cold' Kelvin wave occurs over East Africa. However, there is no unique response of rainfall to MJO events; the inter-event variability seems at least as important as the inter-seasonal variability. Thus, the intrinsic characteristics of each MJO cycle appear as the key feature for understanding the impacts of the oscillation on rainfall, and a statistical approach such as Local Mode Analysis (Goulet and Duvel 2000) may help to document the external factors affecting the relationships between $\mathrm{MJO}$ and rainfall. 
(ii) At interannual time-scales the variability of the long rains is significantly affected by the amplitude of the MJO signal (44\% of the seasonal rainfall variance explained over the period 1979-95). On one hand, strong MJO activity is related to an early onset date and thus to higher rainfall amounts during the first half of the season (March and early April); a longer rainy period is logically associated with higher rainfall amounts (Camberlin and Okoola 2003). On the other hand, the interannual variability of occurrences of extreme events (such as defined above) also strongly impacts the 3-month total amount. The MJO is involved, in that the rainy seasons generally start earlier under conditions of strong activity, and consequently more extreme events are likely to occur in March-April. Over the period 1979-95, the relationships between MJO activity and both onset date and seasonal amount seem, at least partially, to be modulated by ENSO: dry and weak MJO seasons are recorded in the spring seasons following an ENSO event, i.e. during the decaying phase of the associated warm anomalies.

These results contribute to a better understanding of the processes involved in the interannual variability of the East African long rains, by showing that intraseasonal variability associated with the $\mathrm{MJO}$ is one of the most fundamental forcing mechanisms.

\section{ACKNOWLEDGEMENT}

This work was carried out as a part of the LOTI-VCI project funded by the French Programme National d'Etudes de la Dynamique du Climat (PNEDC).

Barlow, M., Wheeler, M. C., Lyon, B. and Cullen, $\mathrm{H}$.

Beltrando, G.

Beltrando, G. and Cadet, D. L.

Beltrando, G. and Duchiron, B.

Black, E., Slingo, J. and

Sperber, K. R.

Camberlin, P. and Diop, M.

Camberlin, P. and Okoola, R. E.

Camberlin, P. and Philippon, N.

Camberlin, P. and Wairoto, J.

1997

Der Mégréditchian, G.

1992

Goff, J. A. and Gratch, S.

1946

2005

1990

1990

1996

2003

2002

2003

2002

\section{REFERENCES}

Le traitement statistique des données multi-dimensionnelles. application à la météorologie, Tome I. Ecole Nationale de la Météorologie, Toulouse, France

'Low-pressure properties of water from -160 to 212F'. Pp. 95-122 in Transactions of the 52nd Annual Meeting of the American Society of Heating and Ventilation Engineers. New York City, USA 
Goulet, L. and Duvel, J.-P.

Griffiths, J. F.

Hastenrath, S., Nicklis, A. and Greishar, L.

Hsu, H.-H. and Lee, M.-Y.

Huffman, G. J., Adler, R. F., Rudolf, B., Schneider, U. and Keehn, P. R.

Indeje, M., Semazzi, F. H. M. and Ogallo, L. J.

Jones, C., Waliser, D. E., Lau, K. M. and Stern, W.

Kalnay, E., Kanamitsu, M., Kistler, R., Collins, W., Deaven, D., Gandin, L., Iredell, M., Saha, S., White, G., Woollen, J., Zhu, Y., Chelliah, M., Ebisuzaki, W., Higgins, W., Janowiak, J., Mo, K. C., Ropelewski, C., Wang, J., Leetmaa, A., Reynolds, R. Jenne, R. and Joseph, D.

Kanamitsu, M., Ebisuzaki, W., Woollen, J., Yang, S.-K., Hnilo, J. J., Fiorino, M. and Potter, G. L.

Kessler, W. S.

Kinter, J. L., Fennessy, M. J., Krishnamurthy, V. and Marx, L.

Liebmann, B. and Smith, C. A

Madden, R. A. and Julian, P. R.

Matthews, A. J.

Nakamura, K.

Nicholson, S. E.

Nicholson, S. E. and Kim, J.

Ogallo, L. J.

Ogallo, L. J., Janowiak, J. and Halpert, M. S.
1996

1997

2000

1959

1993

2005

2004

1996

2002

2001

2004

1996

2000

2004

1968

1988

1988
A new approach to detect and characterize intermittent atmospheric oscillations: Application to the intraseasonal oscillations. J. Atmos. Sci., 57, 2397-2416

The variability of annual rainfall in East Africa. Bull. Am. Meteorol. Soc., 40, 361-362

Atmospheric-hydrospheric mechanisms of climate anomalies in the Western equatorial Indian Ocean. J. Geophys. Res., 98, 219-235

Topographic effects on the eastward propagation and initiation of the Madden-Julian Oscillation. J. Climate, 18, 795-809

The Global Precipitation Climatology Project (GPCP) combined precipitation dataset. Bull. Am. Meteorol. Soc., 78, 5-20

ENSO signals in East African rainfall seasons. Int. J. Climatol., 20, $19-46$

Global occurrences of extreme precipitation and the Madden-Julian Oscillation: Observations and predictability. J. Climate, 17, 4575-4589

The NCEP-NCAR 40 year reanalyses project. Bull. Am. Meteorol. Soc., 77, 437-471

NCEP-DOE AMIP II reanalysis (R-2). Bull. Am. Meteorol. Soc., 83, 1631-1643

Notes and correspondence: EOF representation of the MaddenJulian Oscillation and its connection with ENSO. J. Climate, 14, 3055-3061

An evaluation of the apparent interdecadal shift in the tropical divergent circulation in the NCEP/NCAR reanalysis. J. Climate, 17, 349-361

Description of a complete (interpolated) outgoing longwave radiation dataset. Bull. Am. Meteorol. Soc., 77, 1275-1277

Description of a 40-50 day oscillation in the zonal wind in the tropical Pacific. J. Atmos. Sci., 28, 702-708

Description of global-scale circulation cells in the tropics with a 40-50 day period. J. Atmos. Sci., 29, 1109-1123

Observations of the 40-50 day tropical oscillation-A review. Mon. Weather Rev., 122, 814-837

Propagating mechanisms for the Madden-Julian oscillation. Q. J. R. Meteorol. Soc., 126, 2637-2652

Intraseasonal variability over tropical Africa during northern summer. J. Climate, 17, 2427-2440

'Equatorial westerlies over East Atrica and their climatological significance'. Pp. 43-61 in Geographical Report 3. Tokyo Metropolitan University, Tokyo, Japan

A review of climate dynamics and climate variability in Eastern Africa. Pp. 25-56 in The limnology, climatology and paleoclimatology of the East African lakes. Eds. T. C. Johnson and E. O. Odada. Gordon and Breach Publications, Amsterdam, the Netherlands

The relationship of the El Niño-Southern Oscillation to African rainfall. Int. J. Climatol., 17, 117-135

Relationship between seasonal rainfall in East Africa and the Southern Oscillation. J. Climatol., 9, 31-43

Teleconnection between seasonal rainfall over East Africa and global sea-surface temperature anomalies. J. Meteorol. Soc. Jpn, 66, 807-822 
Okoola, R. E.

1998 Spatial evolutions of the active convective patterns across the Equatorial East Africa region during northern hemisphere spring season using outgoing longwave radiation records. Meteorol. Atmos. Phys., 66, 51-63

1999a A diagnostic study of the eastern Africa monsoon circulation during the northern hemisphere spring season. Int. J. Climatol., 19, 143-168

1999b Midtropospheric circulation patterns associated with extreme dry and wet episodes over Equatorial Eastern Africa during the northern hemisphere Spring. J. Appl. Meteorol., 38, 1161-1169

Philipps, J. and McIntyre, B.

Poccard, I., Janicot, S. and Camberlin, P.

Pohl, B. and Camberlin, P.

Reynolds, R. W., Rayner, N. A., Smith, T. M., Stokes, D. C. and Wang, W.

Saji, N. H., Goswami, B. N., Vinayachandran, P. and Toshio, Y.

Slingo, J., Rowell, D. P., Sperber, K. R. and Nortley, F.

Thompson, B. W.

Trenberth, K. E., Stepaniak, D. P. and Hurrell, J. W.

Trewartha, C.

Wheeler, M. C. and Hendon, H. H.

Wheeler, M. C. and McBride, J. L.
On the predictability of the interannual behaviour of the MaddenJulian Oscillation and its relationship with El Niño. Q. J. R. Meteorol. Soc., 125, 583-609

'Some reflection on equatorial and tropical forecasting'. P. 14 in Technical Memorandum, in No. 7. Kenya Meteorological Department, Nairobi, Kenya

Quality of reanalyses in the tropics. J. Climate, 14, 1499-1510

The earth's problem climate. Methuen and Co, University of

An all-season real-time multivariate MJO index: Development of an index for monitoring and prediction. Mon. Weather Rev., 132, 1917-1932

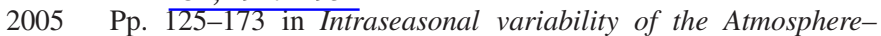
Ocean climate system. Eds. W. K. M. Lau and D. E. Waliser. Praxis Publishing Ltd, Chichester, UK Wisconsin Press, Madison, WI, USA 